\title{
Collective Attention \& Active Consumer Participation in Community Energy Systems
}

\author{
Aikaterini Bourazeri ${ }^{1} \&$ Jeremy Pitt $^{2}$ \\ ${ }^{1}$ Centre for Human Computer Interaction Design \\ Department of Computer Science \\ City, University of London \\ Katerina.Bourazeri@ city.ac.uk \\ ${ }^{2}$ Department of Electrical \& Electronic Engineering \\ Imperial College London \\ SW7 2BT UK \\ j.pitt@imperial.ac.uk
}

\begin{abstract}
Community energy systems, which rely on demand-side self-organisation of energy distribution, can encounter situations in which demand exceeds supply, and unless the community members schedule energy usage by and between themselves, there will be a blackout. This is effectively a collective action dilemma typically modelled as a repeated game and analysed using Game Theory. In this paper, we investigate the situation from an empirical (rather than analytic) perspective using instead a Serious Game. Motivated firstly by Elinor Ostrom's institutional design principles for sustainable common-pool resource management, and secondly by the idea that collective attention is a prerequisite for successful collective action, we present the design and implementation of a Serious Game which both encapsulates (some of) the design principles and promotes collective attention within the game's interface, affordances and interactions. Our experimental results show that as more interface design features which promote collective attention are enabled, then more often successful collective action is observed. These results have, we argue, important implications for Smart Meter design and roll-out programmes, as well as leveraging the active participation of prosumers in innovative operational and management principles for future Smart Grids.
\end{abstract}

Keywords: collective action, collective attention, community energy systems, energy use, serious games

\section{Introduction}

Decentralised Community Energy Systems (dCES) (Bourazeri and Pitt (2014b)) are a type of Smart Grid (SESIG (2013)) which aggregate a number of geographically co-located and electrically inter-connected Smart Houses (i.e. domestic residences equipped with various renewable energy sources (photovoltaic (PV) cells, small wind turbines, etc.)). Of particular interest are 'islanded' dCES which are not connected to (inter)national transmission and distribution systems and have no source of centralised generation and storage (e.g. combined heat/power plant (CHP)). These dCES invert the traditional 'predict and provide' mode of electricity generation and rely instead on demand-side self-organisation, i.e. there is a certain amount of available energy. It is then up to the community members to self-determine the allocation of energy to individual houses, and in particular to cope with the imbalance of generation and usage associated with stochastic energy production with renewable energy sources.

Therefore, dCES can frequently encounter situations in which demand exceeds supply, and unless the community members schedule energy usage by and between themselves, there will be a blackout. This is a collective action dilemma: i.e. a situation demanding a decision between alternative courses of action involving a group of people occupying a common space and needing to coordinate, even if their individual goals may be in conflict with any common goal, and each other's goals. In the dCES case, only if enough members reduce their consumption will the blackout be avoided, but if too few members reduce consumption, then not only do they suffer the loss of reduced consumption while energy supply was possible, but they still experience the inconvenience of a blackout.

Such collective action situations are typically modelled as a repeated game and analysed using Game Theory (e.g. (Ostrom (2014))). However, following Elinor Ostrom, we are concerned that constraints assumed for the purposes of analysis are also assumed to hold in empirical settings (Ostrom (1990) [pp6-7]). One such constraint is awareness, i.e. bringing to the participants' attention that they are impacted in a collective situation, and even when this is recognised, that their (relatively minor) individual actions have had an impact on or made any contribution towards achieving a collectively desirable outcome.

Therefore, in this paper, we investigate a collective action situation in a dCES from a more empirical (rather than analytic) perspective, using instead a Serious Game (Michael and Chen (2005)). Serious games are applications which retain an ele- 
ment of gaming but rather than entertainment they are designed for education, training, or to explore a specific issue (social, environmental, etc.). They have been used in the energy sector to help energy consumers better understand concepts such as resource allocation, electricity prices and grid sustainability. In such gamified environments, players use technology to solve environmental problems including 'green' environment, optimised energy and water infrastructure, sustainable resources and reduced energy use (Deterding et al. (2011)).

The motivation behind using a Serious Game in the dCES setting is to test the proposition that if collective attention is a prerequisite for successful collective action, then increased $\mathrm{col}$ lective attention should lead to increasingly successful collective action. Furthermore, we have used Ostrom's institutional design principles (Ostrom (1990)) to inform the development of the self-organising institution. These design principles are used to define, select and modify the rules used for scheduling and allocating energy in the dCES, and so our Serious Game both encapsulates (some of) the design principles and uses these to promote collective attention through the game's interface, affordances and interactions.

Accordingly, this paper is structured as follows. Section 2 provides more details on the background, motivation and rationale for this work, focusing on dCES, Serious Games and a definition of collective attention. Section 3 presents the design, architecture and implementation of the Serious Game, while Section 4 presents the interface design and implementation, including the encapsulation of (some of) Ostrom's institutional design principles and the interface features used to promote collective attention. Section 5 describes our experimental results, which show that as more interface design features which promote collective attention are enabled, then more often successful collective action is observed. Some future research directions are included in Section 6, and we summarise and conclude in Section 7 with the argument that these results have important implications for Smart Meter design and roll-out programmes, as well as leveraging the active participation of prosumers in innovative operational and management principles for future Smart Grids.

\section{Background \& Motivation}

Collective attention is argued to be a prerequisite for successful collective action in dCES, a type of Smart Grid, and this attention has to be shaped through affordances of the 'humaninfrastructure interface'. A dCES is a socio-technical system with the assistance of technical components such as Smart Meters in which a group of geographically co-located individuals inhabit a community space, and they have to provision to, and appropriate from, a common-pool energy resource. dCES for local power generation and distribution with no connection to aggregators or the rest of the grid can be visualised and represented by a Serious Game.

\section{1. decentralised Community Energy Systems (dCES)}

Power systems and distribution networks face various problematic situations - increased electricity costs, reserve capacity, inconsistent services due to power outages or network overload - which need to be solved either by an aggregated or central control body, comprising a portfolio of smaller units forming a kind of 'collective'. Demand-side management of energy distribution and supply networks can be addressed by a usercentric, self-organising approach (Bourazeri and Pitt (2014b)). dCES group different residences, geographically co-located, and form a Common-Pool Resource (CPR) for locally generated and stored energy. These dCES include PV cells installed on the roofs of the residences, wind turbines and other sources for renewable energy generation and storage. Electric vehicles are used as 'distributed batteries' to help with the issue of storage, and each residence has a number of electrical devices the occupants may wish to use.

To do so, occupants have to provision to, and appropriate from, the CPR. In each dCES, there are two concurrent and codependent provision and appropriation systems, one for energy generation and one for storage. Actions in one system have effects on the other, and instead of each residence generating, storing and using its own energy and thus suffering the consequences of over- or under-production, supply and demand are cross correlated with the common-pool which provides energy to all the residences in the dCES.

In such a collective action situation, occupants need to collaborate and synchronise their individual actions to prioritise the energy distribution and avoid blackouts, achieve a fair resource allocation and sustain the community for the long-term. To achieve a successful collective action, collective attention is pre-required and has to be shaped through a 'human-infrastructure interface' for a socio-technical system (whose objective is the resolution of a collective action problem) (Bourazeri and Pitt (2014a)).

\subsection{Serious Games}

Serious games are digital games, simulations and virtual environments widely used for primary purposes (e.g. teaching, learning and training) other than pure entertainment. They are experiential environments where features such as communication, negotiation, leadership or time management are as important, if not more, as fun or entertainment (Marsh (2011)). Serious games are met quite often in military, government and healthcare with extensive use in education and learning as they are engaging and appealing to all people despite their age or background (Marks et al. (2008); Bulander (2010); Hulst et al. (2008)). Energy systems are a particular area where serious games have been widely deployed to help players better understand concepts such as resource allocation, electricity prices, investment decisions and grid sustainability. A critical appraisal was conducted to identify games relevant to teaching and learning for the energy sector. Different inclusion criteria were specified to find appropriate games; i) primary purpose of the game, ii) subject area, iii) learning outcomes and iv) impact (Connolly et al. (2012)). CityOne, PowerMatrix, Power House and Energy Chickens have been found to satisfy the inclusion criteria, hence they have been included in the review.

IBM has been developing serious games for many years that focus on players' problem-solving skills. In CityOne (IBM 
(2014)), players experience some of the most complicated energy problems currently faced by cities. Players should optimise banking, retail, energy and water in an online, sim-based game, and should complete a series of tasks. They should also improve their city by making revenue and profits, make the environment greener and satisfy the citizens. Moreover, players should manage the network of their city and use new technologies to propose innovative solutions in order to make the water cleaner and banks more prosperous and user-centric. Siemens Energy developed the PowerMatrix game (Siemens (2013)), an online game in which players should sustain a city's energy system. In this game players learn the mechanics and rules of the energy market, and the interactions between the different types of power generation and Smart Grids. PowerMatrix is intended for the general population, where players become energy managers in a rural area and whose aim is to develop a city by creating an intelligent power generation and distribution network. Players should create an energy mix combining different energy sources and, the better the mix the faster the city grows. PowerMatrix informs players about the new forms of energy emphasising power generation but not energy efficiency.

Power House (Reeves et al. (2015)) is an online, multi-player game which visualises players' energy usage based on actual meter readings (there are installed Smart Meters and sensors on players' houses). Players should complete different tasks relating to energy efficiency and management. Energy Chickens game (Orland et al. (2014)) is a web-based serious game application accessed from desktop computers which uses real-time energy consumption data from plug-in devices. Each player has a personalised virtual farm and his/her energy consumption is reflected on the health of the chickens; when energy consumption is low the chickens are healthy and lay eggs, but when consumption is high, the chickens are small and eventually become ill. 288 electrical appliances were monitored for 24 weeks and 61 workers participated. The average energy consumption was reduced by $13 \%$, and $69 \%$ of the participants said that this game helped them to become more energy aware.

These games have been developed to visualise 'real-world' energy problems and provide the required motivation to people to change their energy habits. Players can see the immediate effects of their actions and explore different permutations to achieve better outcomes. A systematic review has been conducted to determine which of the key design features for increasing collective attention in Ostrom-style socio-technical systems have been included in these games. Based on this review, we concluded that some of the design features are omitted, and therefore we developed the Social Mpower game that includes all the key design features that support collective attention for successful collective action.

\subsection{Collective Attention}

Social capital was defined by Ostrom and Ahn as "an attribute of individuals that helps them solve collective action problems" (Ostrom and Ahn (2003b)). Analogously, we (informally) define collective awareness as "an attribute of communities that helps them solve collective action problems" (cf. Sestini (2012)).
We note that in communities where collective awareness is absent, individuals are generally less willing to obey the norms or the rules, or able to understand that their actions have an effect on the community (Fogg (2002)). In communities where collective awareness is present, there is an implicit understanding of the norms and rules which members of the community use to voluntarily regulate their own behaviour, and monitor and evaluate the behaviour of others. In particular, collective awareness does not require a declaration by an empowered individual occupying a designated role (i.e. the exercise of institutionalised power (Jones and Sergot (1996))), but is generated 'from within' by the individuals for the well-being of the collective (i.e. thus in earlier work we focused on interoceptive collective awareness (Pitt et al. (2013))). This is the difference between, for example, in a time of drought, a local authority declaring that "there is a hosepipe ban", and the members of the community observing for themselves that drought conditions obtain, and each consequently assumes (or infers) that one does not use a hosepipe.

Therefore, if we were edging towards a formal definition, it would follow similar lines to the definition of trust given by (Jones (2002)). Jones proposed that it would ordinarily be said that " $A$ trusts $B$ " if two conditions held: firstly, that $A$ believes there is a rule; and secondly, that $A$ expects the behaviour of $B$ to comply with this rule. Collective awareness is, we believe, a similar combination of beliefs and expectations. We would ordinarily say that "collective awareness is present in community $C$ " if each member of a community $C$ has a pertinent set of beliefs (i.e. that there is a community, that $\mathrm{s} / \mathrm{he}$ is a member of the community, that the community operates certain rules, etc.) and a pertinent set of expectations (i.e. that under certain conditions, certain rules are in force, and that members of the community will comply with those rules, etc.). Note that the use of two different modalities, one for belief and one for expectation, means that collective awareness, from this perspective, can be formalised rather differently from mutual knowledge and the infinite prefixing of beliefs ( $A$ believes that $B$ believes that $A$ believes ... etc.).

However, in digitised environments, such as dCES and other socio-technical systems, those physical cues (e.g. there is a drought) may be absent. Moreover, individuals may understand the situation they are in from a micro-level perspective (e.g. reducing individual energy consumption) and might additionally recognise the macro-level requirement (e.g. meeting national carbon dioxide emission pledges); however, they might not be aware of interactions occurring at the meso-level that are critical for mapping one to the other. Therefore, we consider collection attention as "collective awareness plus plus" for digital environments, where the first 'plus' are the cues that indicate that a certain condition obtains, and the second 'plus' is the data propagation and information dissemination mechanisms which ensure that community members are in the know (e.g. classical Athens used marketplace gossip, temples, festivals, parades, etc.) to propagate information to and between citizens as a basis for knowledge aggregation for 'sound' deliberation and decision-making (Ober (2008)).

Collective attention is then, we argue, the bedrock for infor- 
mation dissemination, deliberation, decision making and, crucially, the essential pre-condition for self-organisation and successful collective action in a socio-technical system (cf. Ferscha et al. (2012)). Therefore, we aimed to design a Serious Game of which, it could be ordinarily said, the players demonstrated "collective attention".

The next section describes the architecture of the Serious Game while Section 4 concentrates on the interaction design to create this collective attention in a dCES.

\section{Design, Architecture \& Implementation of Social Mpower}

Social Mpower architecture consists of three main components; Presage 2 agent-based simulation platform (Macbeth et al. (2012)), OpenSimulator application server (Fishwick et al. (2009)), and Imprudence viewer (LindenLab (2015)). The motivation behind this architecture design is the development of a repurposable generic architecture platform which could be used for supporting different Serious Games and interfaces, and therefore all its components are open source and customisable (Bourazeri (2015)).

\subsection{Presage2}

Presage2 simulates large populations of heterogeneous agents implemented in Java, and is used for principled operationalisation and large scale simulation. Presage 2 was extended and adapted to the requirements of Social Mpower Serious Game. Figure 1 illustrates the additions required to build our framework and to simulate the operations of Social Mpower. A Servlet class was included to control each simulation request over Hypertext Transfer Protocol (HTTP). The Servlet class is not presented in Figure 1 as it is the class that calls Presage2, so the entire Figure 1 is wrapped by the Servlet module.

Social Mpower is the module that provides access to the environmental services of Presage 2 and executes the different scenarios. Consumer is the module that handles the current state of the houses and updates the database history based on the operations triggered by the agents in the simulation. The Participant module contains all the necessary operations that Consumer needs to manage the state of the houses. These operations include the calculation of each appliance consumption, the update of the current house and appliance state, as well as the trigger to update the house history service. Finally, the House State is the main entity that holds the structure of the electrical appliances and ensures that all actions submitted by agents are valid in every given time. The House State maintains a list of the electrical appliances, their states and all the necessary information in order for it to be retrieved and mainly used by the Consumer.

\subsection{OpenSimulator}

OpenSimulator is an open source multi-user 3D application platform which supports virtual worlds, environments, and multiple independent regions connected to one centralised grid. OpenSimulator was chosen as it can be easily expanded and

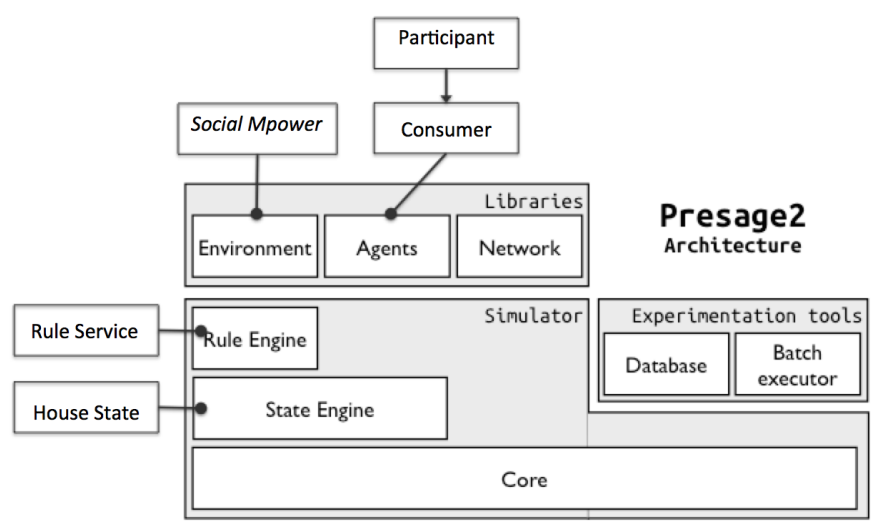

Figure 1: Extended Presage2 architectural block diagram

is compatible with numerous viewers. The first step for using OpenSimulator is to properly configure the database setup. In our case, OpenSimulator connects to a MySQL database. Each region has a unique ID and a specific (x,y) location on the grid. In virtually all cases, the internal address of the region is "0.0.0.0" to enable OpenSimulator listen to any User Datagram Protocol (UDP) connection on any of the server's network interfaces. In OpenSimulator the login service handles the user login and gets information to locate the login response (e.g. specific avatar). This service stores users' details such as username and password and uses those details to identify and authenticate users.

\subsection{Imprudence}

Imprudence is an open source viewer based on Second Life ( $\mathrm{Au}(2008))$ and was chosen to perform a role-playing environment with specific requirements; an energy community system with avatars being the consumers. Imprudence provides different building options, math operations and various geometric shapes such as cube, pyramid, cylinder and sphere that a user can choose from and by changing their position, size, rotation, hollow or skew, these can be transformed into different objects. Various houses with installed PV cells were added to the community, and each house is equipped with electrical appliances such as fridges, washing machines, dishwashers, computers and so on. The default state of each appliance is the off state (except for the fridge which is always on). When a player operates an appliance, a message is displayed on the screen informing him/her that the appliance is on, while the colour of the appliance button changes automatically; from red which implies the appliance is off, it becomes green. Depending on the type of the appliance, it will either stop automatically after a pre-defined time period or the player will turn it off. When an appliance is off, a message is displayed on the screen showing the final consumption and the time the appliance was operating.

\subsection{Overall System Architecture}

Figure 2 shows the overall system architecture of the Social Mpower game. The external environment (player) access the game through the Imprudence viewer, and the player 


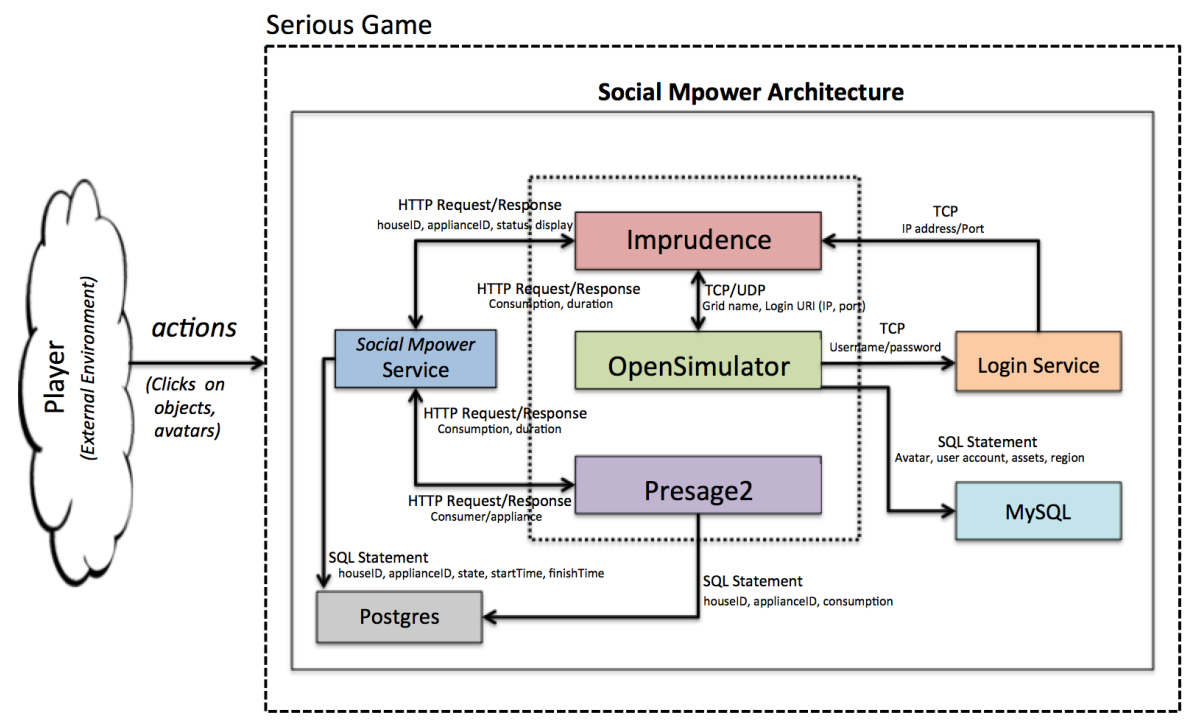

Figure 2: Social Mpower Platform Architecture

controls the avatar who performs different actions that trigger the Social Mpower Service. The Social Mpower Service connects to Imprudence viewer and Presage 2 through HTTP requests/responses. Imprudence viewer can connect to OpenSimulator either with a Transmission Control Protocol (TCP) connection over the Login service or a UDP connection over the region's internal port. Social Mpower architecture includes two different databases; MySQL for OpenSimulator (stores the user's details (i.e. username and password), different avatars and in-world assets and regions) and Postgres for Presage2 (stores the IDs of the in-world houses and appliances, and the energy consumption of each appliance and house). Figure 3 presents the messages exchanged between the Imprudence viewer, OpenSimulator and Presage2. These messages specify the order in which they should occur and explain the result of the system as a result of the interactions. For example, when an avatar interacts with a Smart Meter, the following sequence of events is triggered: 1. Imprudence sends an HTTP request to OpenSimulator with a house ID; 2 . Presage 2 connects and retrieves all appliances' history from the database based on the specific house ID. 3. PostgreSQL database stores the house ID, appliance ID, state of each appliance, start and finish time of each appliance, and the appliance's power consumption; 4. OpenSimulator responds with a list of the overall consumptions to Imprudence; 5. Imprudence sends a second HTTP request to Social Mpower Service to retrieve all houses' consumption; 6. Presage 2 connects and retrieves the appliances' history from the database for all houses; 7 . OpenSimulator responds with a list of the overall consumptions to Imprudence; 8 . Imprudence visually displays the houses' consumption on the Smart Meter.

\section{Interface Design \& Implementation}

Elinor Ostrom proposed eight different socio-economic principles for self-governing institutions that help in sustaining common but limited resources (Ostrom (1990)). These prin-

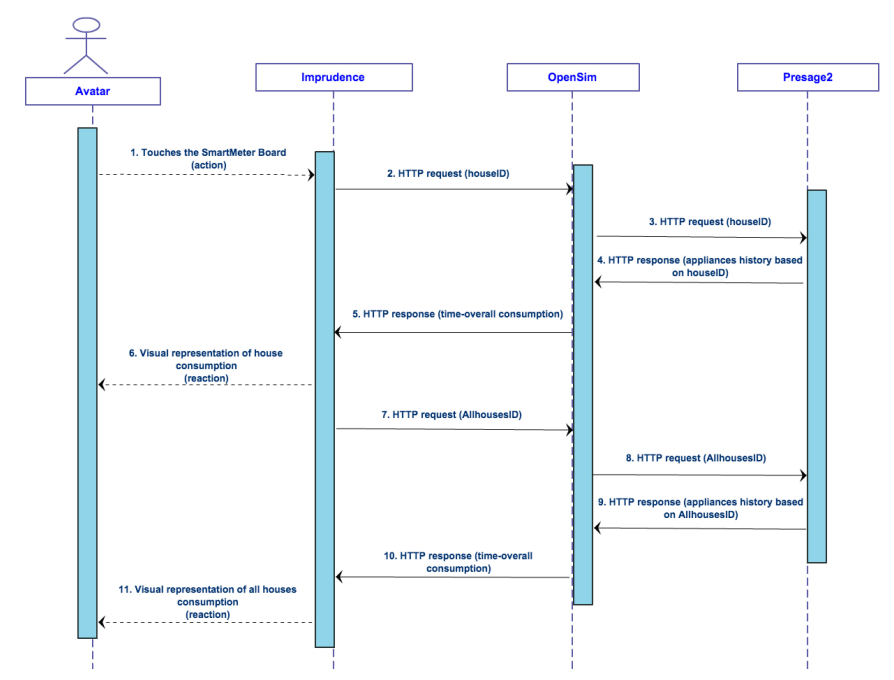

Figure 3: An avatar interacts with a Smart Meter

ciples, which are the basis of self-organisation, define who is a member of an institution, how the resources are managed and distributed, and who is affected by the rules of the institution. Motivated by these institutional design principles for sustainable common-pool resource management and by the idea that collective attention is a prerequisite for successful collective action in dCES, we designed and implemented the interface of Social Mpower game accordingly.

\subsection{Encapsulation of Ostrom's Principles}

Elinor Ostrom's socio-economic principles are necessary and sufficient conditions for designing and setting up an enduring self-organising institution. Different self-interested and autonomous actors need to self-organise in order to share a common, yet limited resource, in a way to avoid its depletion, without even having long-term interests for that resource (Pitt et al. 
(2012, 2011)). These principles are essential elements for an institution and ensure the sustainability of a CPR (Bourazeri and Pitt (2013)). These principles are supported by both the interface and the rules of Social Mpower.

Table 1: Ostrom's Principles visualised in Social Mpower

\begin{tabular}{|l|l|l|}
\hline $\begin{array}{l}\text { Ostrom's Princi- } \\
\text { ples }\end{array}$ & $\begin{array}{l}\text { Visualisation in } \\
\text { Serious Games }\end{array}$ & $\begin{array}{l}\text { Visualisation in } \\
\text { Social Mpower }\end{array}$ \\
\hline $\begin{array}{l}\text { P1 Clearly de- } \\
\text { fined boundaries }\end{array}$ & Game access & Game access \\
\hline $\begin{array}{l}\text { P2 Congruence } \\
\text { between rules and } \\
\text { local environment }\end{array}$ & Collective Action & Collective Action \\
\hline $\begin{array}{l}\text { P3 Collective } \\
\text { choice arrange- } \\
\text { ments }\end{array}$ & $\begin{array}{l}\text { Participatory De- } \\
\text { liberative Assem- } \\
\text { bly }\end{array}$ & $\begin{array}{l}\text { Participatory De- } \\
\text { liberative Assem- } \\
\text { bly }\end{array}$ \\
\hline $\begin{array}{l}\text { P4 Monitoring, } \\
\text { Reporting \& \& } \\
\text { Enforcement }\end{array}$ & $\begin{array}{l}\text { Smart Visualisation \& } \\
\text { Chat }\end{array}$ & $\begin{array}{l}\text { Smart Meter \& } \\
\text { Chat }\end{array}$ \\
\hline $\begin{array}{l}\text { P5 Graduated } \\
\text { Sanctions }\end{array}$ & $\begin{array}{l}\text { Graduated Incen- } \\
\text { tives }\end{array}$ & $\begin{array}{l}\text { Rewarding } \\
\text { Scheme (prize) }\end{array}$ \\
\hline $\begin{array}{l}\text { P6 Conflict reso- } \\
\text { lution Minimal }\end{array}$ & $\begin{array}{l}\text { Conflict resolu- } \\
\text { tion mechanisms }\end{array}$ & $\begin{array}{l}\text { No interference } \\
\text { from external } \\
\text { authorities }\end{array}$ \\
\hline $\begin{array}{l}\text { P7 from interference } \\
\text { recognition external } \\
\text { rights to organise } \\
\text { P8 Nested institu- } \\
\text { tions }\end{array}$ & $\begin{array}{l}\text { Systems-of- } \\
\text { Systems }\end{array}$ \\
\hline
\end{tabular}

Table 1 presents how Ostrom's principles can be visualised in any serious game and which of these principles are visualised in Social Mpower. In Social Mpower, players 'inhabit' a selforganising community, where the rules and norms for the resource allocation and distribution are decided among the players in every gameplay. The game manager informs the players about the available energy that can be consumed, and then it is up to the players how they will self-organise and distribute the available energy among them. Ostrom's institutional principles are axiomatised to ensure a 'fair' share of resources among all players.

Principle P1: Social Mpower simulates an energy community where players share common resources (e.g. energy). Players need a membership to access the game and start playing. People from outside cannot access the game and cannot take part in its norms and rules.

Principle P2: Players are the ones who use the common resources and also the ones who create and define the norms for collaboration and synchronisation of individual actions. In Social Mpower, players self-organise and create their own norms for the resource allocation and distribution.

Principle P3: An 'Assembly' room exists in Social Mpower where all players gather and make common choices and decisions about their energy consumption.

Principle P4: Players control their energy consumption in real-time and see the effects of their individual actions on the community. Smart Meters are assigned this monitoring agency role and display the energy consumption both on individual and collective level.

Principle P5: A rewarding scheme (prize) is introduced to Social Mpower to give a sense of achievement when players avoid an energy problem (e.g. a blackout).

Principle P6: Social Mpower should provide different mechanisms such as negotiation or mediation to resolve disputes when they occur. No conflict-resolution mechanisms have been introduced to Social Mpower, and therefore it depends on the players and how they will resolve any occurred conflict.

Principle P7: No interference from external authorities ensures that the game cannot be controlled or monitored from the external environment .

Principle P8: Nested institutions organised in different layers are allowed for provision, appropriation, monitoring, enforcement and conflict resolutions. Presently, there is only one institution in Social Mpower.

\subsection{Interface Design Features}

Ostrom's principles have been translated into appropriate interface features to assist in designing a virtual dCES and increasing players' collective attention for a successful collective action.

\subsubsection{Interface Cues}

Different interface cues introduced to Social Mpower induce users to participate in a collective action situation. These interface cues are used to transmit various information to players, for example real-time feedback regarding their energy consumption. Players observe the causes and effects of their individual actions on the collective. These cues inform players about upcoming problems and an emphasis is given on players' actions and system's state. Smart Meters inform players about their energy consumption both on individual and collective level, while text messages advise players on how to solve energy problems, i.e. a blackout.

\subsubsection{Visualisation}

Appropriate data presentation and representation is provided, making what is conceptually significant perceptually prominent. Every house in the game has a Smart Meter which includes a line graph with different colours depending on the information displayed each time. These Smart Meters display the energy consumption of each house and the total community consumption (see Figure 4).

\subsubsection{Social Networking}

Players are physically located in different rooms and on different computers, and they can only communicate through the social networking (chat), which is available on the game interface. There are three different types of text chat:

- Local chat - everybody within a range of 20 meters can access the in-game communication (see Figure 5). There is also the 'shout' option with a range of 100 meters and the 'whisper' option with a range of 10 meters. 


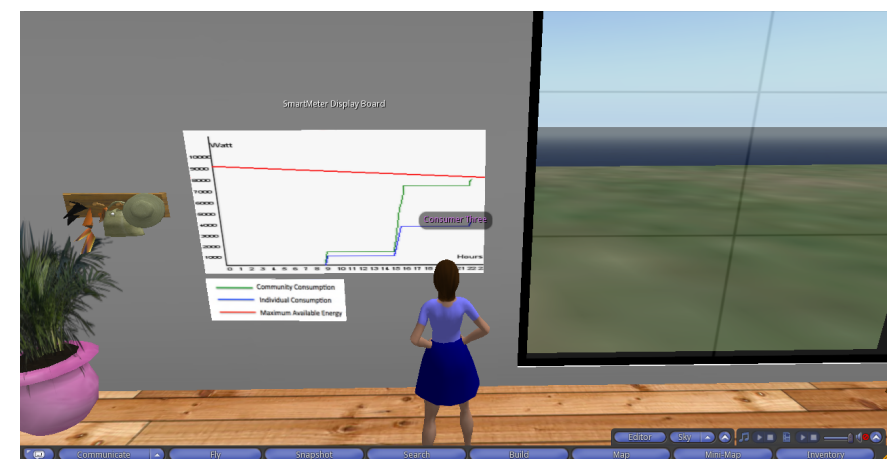

Figure 4: Smart Meter

- Group chat - send messages to a group. Players can only communicate with other players that are included in their friend list or with other players within a specific chat range.

- IM - private one-to-one communication without a limited range distance. When a player is offline, $\mathrm{s} /$ he can receive up to 25 messages the next time s/he gets online.

These different communication modes have been included to let players form various networking interactions with their co-players. The social networking interaction between players is formed within a collective interaction system where players should negotiate their individual actions to achieve a common goal. The social interaction itself encourages players to form a community and establishes common goals and actions. To achieve their common goals, players are in constant negotiation and in some cases conflicts, that should be resolved among them.

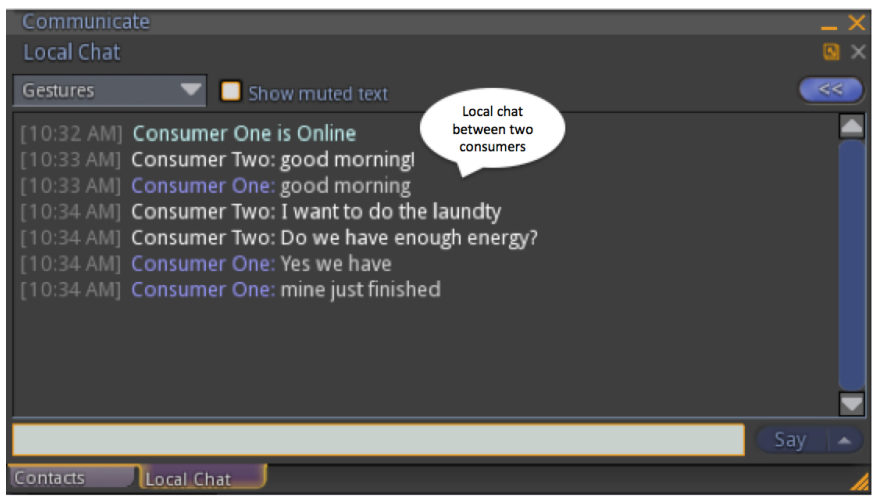

Figure 5: Social Networking

\subsubsection{Feedback}

Players should know that their ('small', individual) action $X$ contributes to some ('large', collective) action $Y$ which achieves beneficial outcome $Z$. In many collective action situations, individual players may not recognise that their small actions can contribute to resolve a problem, especially if the effect is indirect, undetectable or long-term (e.g. climate change). Realtime feedback (see Figure 6) enables players to proactively coordinate their behaviour and take collective actions to prevent energy problems.

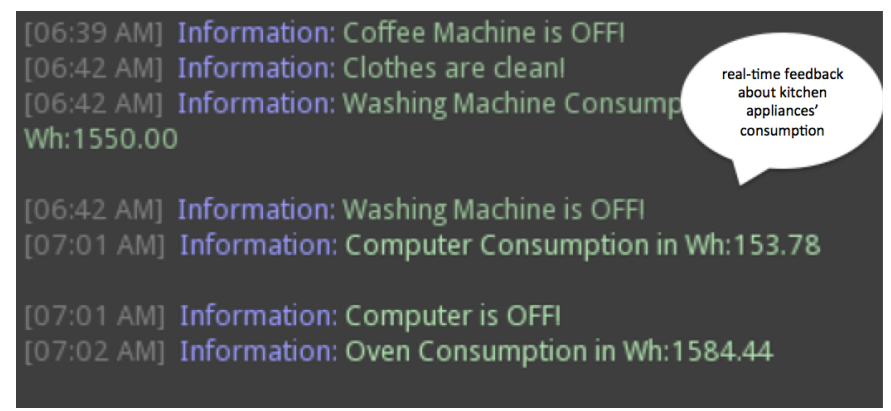

Figure 6: Real-time feedback

\subsubsection{Incentives}

Rewards and incentives typically in the form of social capital (itself identified as an attribute of individuals that helps them with solving collective action problems) (Ostrom and Ahn (2003a)) give players a sense of achievement when they avoid an energy problem. Introducing different reward mechanisms (see Figure 7) to Social Mpower benefit players both on individual and collective level, i.e. promoting and supporting successful collective action.

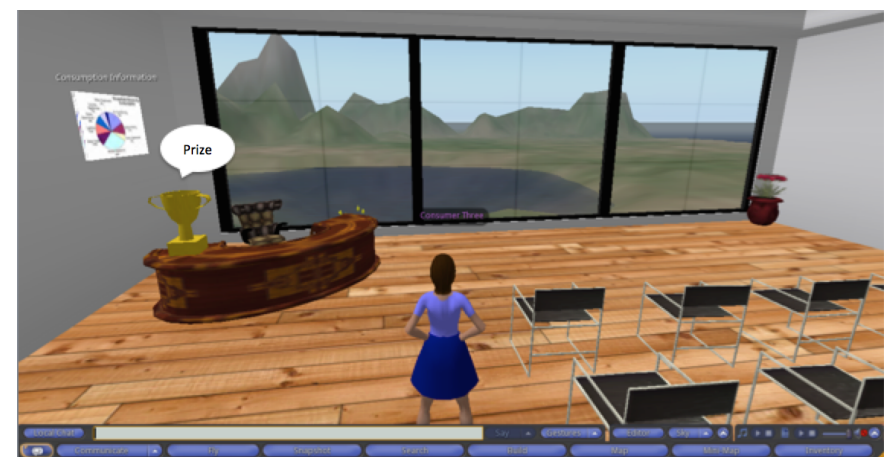

Figure 7: Incentives (Reward)

\subsection{Social Mpower Serious Game}

Social Mpower is a representation of a dCES for local power generation and distribution, which enables players to observe the immediate weather changes and understand the use of renewable energy. Power generation results from PV cells, which are the only energy resources for the community, installed on the roofs of the virtual houses. The virtual houses are connected so that they consume the produced power and eventually, share any remaining energy with the rest of the community. The produced energy is stored in each residence in appropriate energy storage systems (e.g. batteries). 


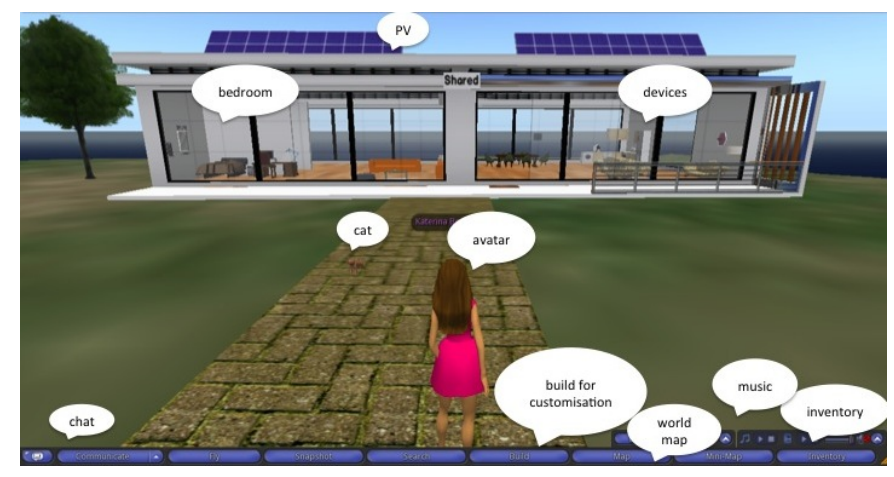

Figure 8: Social Mpower virtual world

The virtual houses include different rooms such as kitchen, dining room, living room and bedrooms. The kitchen is equipped with electrical appliances such as dishwasher, washing machine, fridge, oven and coffee machine. The rest of the house includes TV, computers, sofas, chairs, tables, desks, beds, bookcases and plants so that players feel at home. There is a 'build' option on the game interface which enables players to personalise their houses. Avatars are customisable to meet players' preferences and different animals such as dog, cats, turtles and ducks have been included for an engaging and enjoyable in-game experience. There is also an inventory where players can save and store their assets and objects, and players communicate only through chat (see Figure 8).

The rules of the game are defined by the game manager and include the following:

1. Players can visit other players' houses, but they cannot interact with their appliances.

2. When players consume all the available energy, they should immediately stop playing and turn off all their appliances.

3. Players can only communicate through chat, which is available on the game interface.

4. For a successful gameplay (win state), all players should complete all their tasks within the predefined available energy.

5. Players lose when they are out of energy without having completed their tasks (lose state).

6. Players can only gather at the 'Assembly' room where they can see the consumption of the whole community.

The game manager is the central entity who initiates the game by sending a start message to the players. When the game starts, the game manager sends a play message to all the players. When the game is over (stop message), the game manager evaluates the game based on the successful completion of the tasks within the energy limit and gives the rewards. If players exceed their available energy, the game manager immediately stops the game (any appliance that is ON is turned off) and the players receive an alert with a 'GAME OVER' message.

\section{Results \& Analysis}

\subsection{Experimental Setup}

Social Mpower is a multiplayer game and in each gameplay, which lasts about 30 minutes, there is a group of maximum 3 players co-located in the same virtual world. The game manager hands out the game instructions and checks that all the experimental conditions are met (e.g. players fully understand the instructions, no external factor intervenes in the gameplay, players only communicate through chat). The game manager (located on a different computer) assigns the available energy to all players and then the game starts. Players choose their avatar and house according to their real-life circumstances and within a specific amount of available energy they should complete the following household activities:

- Do laundry

- Wash the dishes

- Cook a meal

- Drink coffee

\section{- Watch TV}

- Use the computer

The goal of the game is players to complete all of the above tasks without exceeding their available energy. If players exceed their available energy, an energy problem will occur from excessive demand. This will cause temporary congestion or energy shortage that causes a blackout. When the gameplay finishes, the game manager hands out the questionnaires the players should complete. The questionnaire includes the following questions:

1. Did the Smart Meter enable you to anticipate an energy problem?

2. Did you use chat to inform others there was an upcoming energy problem?

3. Did you use chat to coordinate with others a plan or schedule to avoid an energy problem?

4. Did the real-time feedback help you to avoid energy problems?

5. Did the rewards give you a sense of achievement in avoiding an energy problem?

Players have to say to what extent they agree or disagree with these questions. We use a typical five-level Likert-type scale (1. Strongly disagree, 2. Disagree, 3. Neither agree nor disagree, 4. Agree, 5. Strongly agree). In total, 87 players took part in the gameplays, 48 males with an average age of 38 and 39 females with an average age of 32 . No incentives were provided. When players complete the questionnaires, the debriefing session starts. During the debriefing session, the game manager asks questions about the overall game experience and keeps notes. Players discuss if they were aware of an energy problem, which actions led them to experience an energy problem, 
how willing they were to collaborate with their co-players and so on. All gameplays are videotaped should the need arise to supplement the questionnaires and the debriefing sessions. All the collected data are then transcribed.

\subsection{Experimental Results}

Logistic regression (Hosmer $\mathrm{Jr}$ and Lemeshow (2004); Menard (2002)), a direct probability model, was used to calculate the probability of getting a certain outcome given certain values; the probability that players' collective attention is increased leading to successful collective action (e.g. avoid possible energy problems) when the different interface design features (visualisation - Smart Meter, social networking - chat, incentives - rewards \& real-time feedback) are enabled on the Social Mpower interface.

Table 2 presents a summary of the results; the percentage of players who managed to coordinate their actions and avoid an energy problem when the different interface design features were enabled on the interface of Social Mpower game.

Table 2: Percentage of players who managed to coordinate their actions

\begin{tabular}{|c|c|}
\hline Interface Features & $\begin{array}{l}\text { Percentage of players } \\
\text { who managed to coor- } \\
\text { dinate }\end{array}$ \\
\hline No Interface Feature is present & $43.7 \%$ \\
\hline Smart Meter & $55.2 \%$ \\
\hline Rewards & $56.3 \%$ \\
\hline Real-Time Feedback & $60.9 \%$ \\
\hline Chat & $64.4 \%$ \\
\hline Smart Meter $\mathcal{E}$ Rewards & $55.2 \%$ \\
\hline $\begin{array}{l}\text { Smart Meter E Real-Time } \\
\text { Feedback }\end{array}$ & $57.5 \%$ \\
\hline Chat $\mathcal{F}$ Rewards & $58.6 \%$ \\
\hline $\begin{array}{l}\text { Real-Time Feedback } \mathcal{E} \text { Re- } \\
\text { wards }\end{array}$ & $59.8 \%$ \\
\hline Chat $\mathcal{E}$ Real-Time Feedback & $60.9 \%$ \\
\hline Smart Meter $\mathcal{E}$ Chat & $65.5 \%$ \\
\hline $\begin{array}{l}\text { Smart Meter } \mathcal{E} \text { Rewards } \mathcal{F} \\
\text { Real-Time Feedback }\end{array}$ & $54 \%$ \\
\hline $\begin{array}{l}\text { Real-Time Feedback } \mathcal{E} \text { Re- } \\
\text { wards E Chat }\end{array}$ & $60.9 \%$ \\
\hline $\begin{array}{l}\text { Smart Meter E Real-Time } \\
\text { Feedback E Chat }\end{array}$ & $65.5 \%$ \\
\hline $\begin{array}{l}\text { Smart Meter } \mathcal{E} \text { Rewards } \mathcal{F} \\
\text { Chat }\end{array}$ & $65.5 \%$ \\
\hline $\begin{array}{l}\text { All Interface Features are } \\
\text { present }\end{array}$ & $66.7 \%$ \\
\hline
\end{tabular}

Figure 9 presents the output of our model including only the intercept; players are able or not to coordinate their individual actions and avoid an energy problem when none of the interface design features are enabled on the Social Mpower interface. Based on the feedback we received at the end of every gameplay and given the base rates of these two action options (no coordination $\&$ coordination) $49 / 87=56.3 \%$ of players did not manage to coordinate their individual actions with their coplayers, and therefore only $38 / 87=43.7 \%$ of them managed to avoid an energy problem. In this model, the best strategy is to predict, for every case, that players coordinate their individual actions and prevent an energy problem (e.g. blackout). Using this strategy (binary logistic regression), we will be correct $43.7 \%$ of the times. Before we use this information to classify the percentage of players who coordinated or not, we need a decision rule. Our decision rule will be in the following form: if the probability of the event is greater than or equal to the above prediction $(43.7 \%$ of players will coordinate their individual actions), we shall predict that the event will take place. The same decision rule will be applied to different combinations of interface features, and some indicative examples are presented below.

\begin{tabular}{|c|c|c|c|c|c|}
\hline \multicolumn{6}{|c|}{$\begin{array}{c}\text { Comparison between predicted and actual coordination when no Interface } \\
\text { Design Feature is enabled }\end{array}$} \\
\hline \multirow{3}{*}{\multicolumn{2}{|c|}{ Observed }} & & \multicolumn{3}{|c|}{ Predicted } \\
\hline & & & \multicolumn{2}{|c|}{ Coordination } & \multirow{2}{*}{$\begin{array}{c}\text { Percentage } \\
\text { Correct }\end{array}$} \\
\hline & & & No & Yes & \\
\hline \multirow{3}{*}{ Step 0} & \multirow[t]{2}{*}{ Coordination } & No & 0 & 49 & .0 \\
\hline & & Yes & 0 & 38 & 100.0 \\
\hline & \multicolumn{2}{|c|}{ Overall Percentage } & & & 43.7 \\
\hline
\end{tabular}

Figure 9: Comparison between the predicted and actual coordination when no Interface Design Feature is enabled

Figure 10 presents the output of the decision rule when Smart Meter is enabled on the Social Mpower interface. This rule correctly classifies $12 / 38=31.6 \%$ of the players, when the predicted event (coordinate when the Smart Meter is enabled on the game interface) was observed. This is known as the sensitivity of prediction, the $\mathrm{P}$ (correct $\mid$ event did occur) that is, the percentage of occurrences correctly predicted. This rule also classifies $13 / 49=73.5 \%$ of the players when the predicted event was not observed. This is known as the specificity of prediction, the $\mathrm{P}$ (correct $\mid$ event did not occur), that is, the percentage of non-occurrences correctly predicted. Overall our predictions were correct $48 / 87$ times, with an overall success rate of $55.2 \%$. Recalling that the prediction of coordination is $43.7 \%<55.2 \%$ for the model including only the intercept, these results show that the Smart Meter increased players' collective attention and therefore they achieved a successful collective action.

Figure 11 presents the output of the decision rule when all the interface design features (Smart Meter, Chat, Real-Time Feedback and Rewards) are enabled on the Social Mpower interface. $66.7 \%$ of the players better coordinated their individual actions and behaviours, and avoided energy problems when all the interface design features were enabled on the Social Mpower interface.

\subsection{Discussion}

Section 5.2 presented the experimental results obtained using logistic regression. In the first round, players were trying 


\begin{tabular}{|c|c|c|c|c|c|}
\hline \multicolumn{6}{|c|}{$\begin{array}{c}\text { Comparison between predicted and actual coordination when SmartMeter is } \\
\text { enabled }\end{array}$} \\
\hline \multirow{3}{*}{\multicolumn{3}{|c|}{ Observed }} & \multicolumn{3}{|c|}{ Predicted } \\
\hline & & & \multicolumn{2}{|c|}{ Coordination } & \multirow{2}{*}{$\begin{array}{c}\text { Percentage } \\
\text { Correct } \\
\end{array}$} \\
\hline & & & No & Yes & \\
\hline \multirow{3}{*}{ Step 1} & \multirow[t]{2}{*}{ Coordination } & No & 36 & 13 & 73.5 \\
\hline & & Yes & 26 & 12 & 31.6 \\
\hline & \multicolumn{2}{|c|}{ Overall Percentage } & & & 55.2 \\
\hline
\end{tabular}

Figure 10: Comparison between the predicted and actual coordination when SmartMeter is enabled

\begin{tabular}{|c|c|c|c|c|c|}
\hline \multicolumn{6}{|c|}{$\begin{array}{l}\text { Comparison between predicted and actual coordination when all Interface } \\
\text { Design Features are enabled }\end{array}$} \\
\hline \multirow{3}{*}{\multicolumn{3}{|c|}{ Observed }} & \multicolumn{3}{|c|}{ Predicted } \\
\hline & & & \multicolumn{2}{|c|}{ Coordination } & \multirow{2}{*}{$\begin{array}{c}\text { Percentage } \\
\text { Correct } \\
\end{array}$} \\
\hline & & & No & Yes & \\
\hline \multirow{3}{*}{ Step 1} & \multirow[t]{2}{*}{ Coordination } & No & 37 & 12 & 75.5 \\
\hline & & Yes & 17 & 21 & 55.3 \\
\hline & \multicolumn{2}{|c|}{ Overall Percentage } & & & 66.7 \\
\hline
\end{tabular}

Figure 11: Comparison between the predicted and actual coordination when all Interface Design Features are enabled

to prevent energy problems without any of the interface design features being enabled on the game interface. In this case, the percentage of players who managed to self-organise and coordinate their individual actions was quite low, only $43.7 \%$ of those players avoided the energy problem (i.e. a blackout). Gradually, the different interface features were enabled on the game interface and we measured the impact (if any) of these interface features on the players' collective attention. When Smart Meter was enabled on the interface there was a small increase on players' coordination percentage and $55.2 \%$ of them managed to coordinate their actions. When rewards were enabled on the game interface, $56.3 \%$ of the players prevented a blackout and when real-time feedback was enabled, this percentage was increased to $60.9 \%$. The largest increase occurred when chat was enabled, indicating that chat is a strong feature (on it's own) which increased players' collective attention and helped them to better communicate and coordinate their actions. In the next round, the different combinations of interface design features were enabled on the game interface. When Smart Meter and rewards were enabled on the interface, only $55.2 \%$ of the players managed to avoid an energy problem, indicating that the combination of these two interface features is not a strong mechanism to promote self-organisation among players. The best combinations for increasing collective attention and promoting coordination of players' individual actions are; Smart Meter and chat $(65.5 \%)$, Smart Meter, real-time feedback and chat $(65.5 \%)$ and, SmartMeter, rewards and chat $(65.5 \%)$. The experimental results proved our experimental hypothesis (the more interface design features which promote collective attention are enabled on the Social Mpower interface, the better players could coordinate their individual actions and decisions for achieving a successful collective action situation, i.e. avoid a blackout) as the percentage of players, who managed to avoid a blackout when all interface design features were enabled on the game interface, increased to $66.7 \%$.

The data analysis helped us to identify the pattern that these different interface features followed and which of these interface design features are strong mechanisms/incentives for users. Players found disturbing the fact that there was no alarm or buzzer on the Smart Meter to warn them that energy consumption reaches the limit. They had to visit the Smart Meter periodically to check how much energy was left over for consumption. According to their feedback, it would be more useful if there was an alarm to inform them about incipient energy problems. With such an alarm there would be no need for players to go back to the Smart Meter and check the available amount of energy. Some of their comments include:

"Smart Meter should give an alarm to inform the customer about the energy problem."

"There should be an alarm to tell user to turn off appliances instead of going to the Smart Meter."

\section{"Have a buzzer to remind the energy problem is approaching."}

Rewards were not a strong incentive for players. In Social Mpower, collective action is not being reinforced by extrinsic motivation such as rewards, although we have included a prize that a team can win at the end of the gameplay. The prize has been included to test if players are encouraged to better resolve collective action problems, but people have different attitudes towards gains and losses, (Kahneman (2003)) and therefore different kinds of rewards should be introduced to test whether players are incentivised and encouraged by them. From a socio-economic perspective, the factors of competition and social comparison have an effect on people who focus on absolute rather than relative victory, meaning that their individual winning is more important than the community winning (Ferdman (Feb 8, 2016)), and all these factors have a strong effect on communities which share common resources with longterm interest. Real-time feedback could be enhanced if players had a visual representation of the amount of energy required for an electrical appliance to complete its cycle. When players know exactly how much energy the appliances consume, they can better arrange the schedule of their use and coordinate their actions accordingly.

Social Mpower game has been developed aiming to promote collective attention and active consumer participation. Even though there were no immediate effects on players' real-lives, we can argue that our game can be used as an educational tool and therefore we quote some players' comments to justify this argument:

"Very nice the idea of the game. It helped me to think more seriously about environmental issues and especially about 
energy problems.”

"It is a great idea to encourage people to use Smart Meters and share energy responsibilities."

"The Smart Meter showing our energy consumption was insightful about the energy consumption arising from daily household activities."

\section{Future Work}

There are several aspects of research we consider for future work. These include the improvement of the Social Mpower interface with additional features, players' access to the game and the transition from a virtual world to real-world applications (e.g. 'smart' houses). Our goal is to encapsulate to Social Mpower game all of Elinor Ostrom's principles for enduring self-organising institutions. In communities where individual goals are in conflict with the common goal, and each other's goals, its members often behave in selfish ways, creating a need for agile conflict resolution mechanisms. Institutions and communities should provide fast access to conflict resolution mechanisms such as negotiation and mediation which can resolve occurred disputes in short time and low cost. These mechanisms can even preserve and strengthen the relationships among the community members (Pitt et al. (2011)). A neutral third party could potentially assist the disputing players through open communication and different negotiation techniques. Social Mpower should become part of a larger system with multiple institutions organised in different layers, to test how selforganisation and successful collective action can be achieved when the involved parties (e.g. players belonging to different communities) should effectively communicate to notice and prevent energy problems.

Social Mpower should become an online multi-player game with multiple independent players forming teams and playing over the Internet. Becoming a massive multi-player game would enable us to further test the effectiveness of collective attention since there will be many players playing at the same time, synchronising their individual actions and setting common goals. Finally, other research directions include gamification of the 'smart' houses, so that appliances in the game could be directly related to appliances in the 'smart' house, and actions in the real world could affect the state of the game. In this context, the use of the Smart Meter for visualisation and synergy of computational intelligence with human (social) intelligence could have a profound impact on collective action (Bourazeri (2015)).

\section{Conclusions}

The aim of this paper was, in the context of dCES, to investigate the proposition that an increase in collective attention would lead to an increase in successful collective action, i.e., in the specific context, to self-organise the energy demand to avoid a blackout. The contributions of this paper are:
- a (preliminary) definition of collective attention, as distinct from mutual knowledge;

- the design and implementation of a Serious Game for a dCES, whose interface includes a number of mechanisms and features to increase collective attention; and

- experimental results which show that as the number of features for increasing collective attention were increased, then there was a corresponding increase in successful collective action.

In conclusion, we would argue that, as information systems 'collide' and converge with instrumented infrastructure like the electrical grid, this work has some significant implications for 'Smart' Meters, Grids, and even cities. Our main contentions are threefold. Firstly, that in order to be most effective, 'Smart' Meters should be user-facing and user-centric, and that their deployment should support - through visualisation, social networking, etc. - opportunities for pro-social behaviour and in particular collective action.

Secondly, we contend that it is possible to offer Smart Grid solutions which are based on relational economies and social capital rather than transactional economies, although this needs to be fully tested with all of Ostrom's principles implemented (in particular, it is often either the lack of enforceable sanctions, which should be applied by an external authority and is not; or the restriction of the right to self-organise, which should not be applied by an external authority, and often is, which collapses the community).

Finally, and perhaps most importantly, we believe it is essential to democratise the Smart Grid (Sanduleac et al. (2011)), by ensuring that the generators of the data are its primary beneficiaries. Furthermore, the Smart Meter should be an open platform with well-defined APIs, which can be used to develop both physically co-located and 'islanded' community energy systems considered here, but also virtual community energy systems of like-minded individuals. Ultimately, we would argue that this prosocial approach to demand-side energy management offers an opportunity to empower users in their different roles in (or relations with) infrastructure (e.g. prosumer, investor, citizen, (charitable) donor, etc.) and that this will lead to more responsive and sustainable energy use.

\section{REFERENCES}

Au, W. J., 2008. The making of second life. Collins.

Bourazeri, A., 2015. Collective awareness in self-organising socio-technical systems.

Bourazeri, A., Pitt, J., 2013. Serious game design for inclusivity and empowerment in smartgrids. In: First International Workshop on Intelligent Digital Games for Empowerment and Inclusion.

Bourazeri, A., Pitt, J., 2014a. An agent-based serious game for decentralised community energy systems. In: PRIMA 2014: Principles and Practice of Multi-Agent Systems. Springer, pp. 246-253.

Bourazeri, A., Pitt, J., 2014b. Collective awareness for collective action in socio-technical systems. In: Self-Adaptive and Self-Organizing Systems Workshops (SASOST), 2014 IEEE Eighth International Conference on. IEEE, pp. 90-95. 
Bulander, R., 2010. A conceptual framework of serious games for higher education: Conceptual framework of the game innov8 to train students in business process modelling. In: e-Business (ICE-B), Proceedings of the 2010 International Conference on. IEEE, pp. 1-6.

Connolly, T. M., Boyle, E. A., MacArthur, E., Hainey, T., Boyle, J. M., 2012. A systematic literature review of empirical evidence on computer games and serious games. Computers \& Education 59 (2), 661-686.

Deterding, S., Dixon, D., Khaled, R., Nacke, L., 2011. From game design elements to gamefulness: defining gamification. In: Proceedings of the 15th International Academic MindTrek Conference: Envisioning Future Media Environments. ACM, pp. 9-15.

Ferdman, R. A., Feb 8, 2016. Why people cheat. The Washington Post.

Ferscha, A., Zia, K., Gollan, B., 2012. Collective attention through public displays. In: Self-Adaptive and Self-Organizing Systems (SASO), 2012 IEEE Sixth International Conference on. IEEE, pp. 211-216.

Fishwick, P., et al., 2009. An introduction to opensimulator and virtual environment agent-based $m \& s$ applications. In: Simulation conference (WSC), proceedings of the 2009 winter. IEEE, pp. 177-183.

Fogg, B., 2002. Persuasive technology: Using computers to change what we think and do (interactive technologies). Ubiquity.

Hosmer Jr, D. W., Lemeshow, S., 2004. Applied logistic regression. John Wiley \& Sons.

Hulst, A., Muller, T., Besselink, S., Coetsier, D., Roos, C., 2008. Bloody serious gaming: experiences with job oriented training. In: Proceedings: Interservice/Industry Training, Simulation, and Education Conference (I/ITSEC).

IBM, 2014. City one. real world game, real world impact. URL http://creativity-online.com/work/ibm-cityone/21496

Jones, A. J., 2002. On the concept of trust. Decision Support Systems 33 (3), 225-232.

Jones, A. J., Sergot, M., 1996. A formal characterisation of institutionalised power. Logic Journal of the IGPL 4 (3), 427-443.

Kahneman, D., 2003. Maps of bounded rationality: Psychology for behavioral economics. The American economic review 93 (5), 1449-1475.

LindenLab, 2015. Imprudence viewer.

URL http://wiki.kokuaviewer.org/wiki/Kokua/Downloads

Macbeth, S., Pitt, J., Schaumeier, J., Busquets, D., 2012. Animation of selforganising resource allocation using presage2. In: SASO. pp. 225-226.

Marks, S., Windsor, J., Wünsche, B., 2008. Evaluation of game engines for simulated clinical training. In: New Zealand Computer Science Research Student Conference 2008. pp. 92-99.

Marsh, T., 2011. Serious games continuum: Between games for purpose and experiential environments for purpose. Entertainment Computing 2 (2), 6168.

Menard, S., 2002. Applied logistic regression analysis. Vol. 106. Sage.

Michael, D. R., Chen, S. L., 2005. Serious games: Games that educate, train, and inform. Muska \& Lipman/Premier-Trade.

Ober, J., 2008. Democracy and knowledge: Innovation and learning in classical Athens. Princeton University Press.

Orland, B., Ram, N., Lang, D., Houser, K., Kling, N., Coccia, M., 2014. Saving energy in an office environment: A serious game intervention. Energy and Buildings 74, 43-52.

Ostrom, E., 1990. Governing the Commons. CUP, Cambridge.

Ostrom, E., 2014. Collective action and the evolution of social norms. Journal of Natural Resources Policy Research 6 (4), 235-252.

Ostrom, E., Ahn, T., 2003a. Foundations of Social Capital. Edward Elgar Pub. Ostrom, E., Ahn, T.-K., 2003b. Foundations of social capital.

Pitt, J., Bourazeri, A., Nowak, A., Roszczynska-Kurasinska, M., Rychwalska, A., Santiago, I. R., Sanchez, M. L., Florea, M., Sanduleac, M., 2013. Transforming big data into collective awareness. Computer 46 (6), 40-45.

Pitt, J., Schaumeier, J., Artikis, A., 2011. The axiomatisation of socioeconomic principles for self-organising systems. In: Self-Adaptive and SelfOrganizing Systems (SASO), 2011 Fifth IEEE International Conference on. IEEE, pp. 138-147.

Pitt, J., Schaumeier, J., Busquets, D., Macbeth, S., 2012. Self-organising common-pool resource allocation and canons of distributive justice. In: SelfAdaptive and Self-Organizing Systems (SASO), 2012 IEEE Sixth International Conference on. IEEE, pp. 119-128.

Reeves, B., Cummings, J. J., Scarborough, J. K., Yeykelis, L., 2015. Increasing energy efficiency with entertainment media an experimental and field test of the influence of a social game on performance of energy behaviors. Environment and Behavior 47 (1), 102-115.
Sanduleac, M., Eremia, M., Toma, L., Borza, P., 2011. Integrating the electrical vehicles in the smart grid through unbundled smart metering and multi-objective virtual power plants. In: Innovative Smart Grid Technologies (ISGT Europe), 2011 2nd IEEE PES International Conference and Exhibition on. IEEE, pp. 1-8.

SESIG, 2013. Smart Energy Special Interest Group: The role of community energy systems in the UK resilient energy supply. Tech. rep., Innovate UK.

Sestini, F., 2012. Collective awareness platforms: Engines for sustainability and ethics. Technology and Society Magazine, IEEE 31 (4), 54-62.

Siemens, 2013. Powermatrix.

URL http: //www . powermatrixgame.com/ 